\title{
CUIDADO FAMILIAL NO MUNDO DA CRIANÇA E ADOLESCENTE QUE VIVEM COM HIV/AIDS ${ }^{1}$
}

\author{
FAMILY CARE IN THE CHILD AND THE ADOLESCENT WORLD \\ LIVING WITH HIV/AIDS
}

\section{CUIDADO FAMILIAR EN EL MUNDO DEL NIÑO Y DEL ADOLESCENTE QUE VIVEN CON VIH/SIDA}

\author{
Maria da Graça Corso da MotTa * \\ Aline Cammarano Ribeiro ${ }^{* *}$ \\ Paula Manoela Batista Poletto ${ }^{* * *}$ \\ HELENA BECKER ISSI ${ }^{* * * *}$ \\ Nair Regina Ritter Ribeiro ${ }^{* * * * *}$ \\ Stela Maris de Mello PAdOIN ${ }^{* * * * *}$
}

\begin{abstract}
RESUMO
Objetivo: desvelar a percepção do familiar/cuidador em relação ao cotidiano medicamentoso na perspectiva da criança e do adolescente que vivem com HIV/AIDS. Método: A pesquisa é qualitativa, com a utilização do método criativo e sensível, realizada nos municípios de Porto Alegre e Santa Maria/RS, com a participação de 12 familiares/cuidadores, no período de 2006 a 2010, e aprovada pelo Comitê de Ética em Pesquisa das instituições envolvidas. Resultados: A partir da análise temática emergiram as categorias: implicações do cotidiano medicamentoso para as famílias e cuidado familial na convivência com a doença. No cotidiano da criança ou adolescente que vive com HIV/AIDS a família percebe as dificuldades do uso de antirretrovirais, a transição da fase infância/adolescência, as múltiplas faces do viver com HIV/AIDS. Conclusão: O cuidado familial acontece
\end{abstract}

\footnotetext{
${ }^{1}$ Resultados integram pesquisa denominada: Impacto de Adesão ao tratamento antirretroviral em crianças e adolescentes, na perspectiva da família, da criança e do adolescente, nos municípios de Porto Alegre e Santa Maria/RS, sob o contrato no: ED03756/2006 (UNESCO); TRPJ no As -3833/2006, financiado pelo Departamento de HIV/AIDS e Hepatites Virais do Ministério da Saúde, Organização das Nações Unidas para a Educação, Ciência e a Cultura.

*Enfermeira. Docente da Escola de Enfermagem e do Programa de Pós-Graduação em Enfermagem da Universidade Federal do Rio Grande do Sul/UFRGS. E-mail: cevida_enfermagem@yahoo.com.br

${ }^{* *}$ Enfermeira. Docente do Curso de Graduação em Enfermagem da Universidade Federal de Santa Maria/UFSM/CESNORS/ Palmeira das Missões. Estudos do Cuidado à Saúde nas Etapas da Vida - CEVIDA. E-mail: alinecammarano@gmail.com

${ }^{* * *}$ Mestranda em Enfermagem do Programa de Pós-Graduação em Enfermagem da Universidade Federal do Rio Grande do Sul/UFRGS. Membro do Grupo de Estudos do Cuidado à Saúde nas Etapas da Vida - CEVIDA. E-mail: paulampoletto@ gmail.com

${ }_{* * * *}$ Doutoranda em Enfermagem pelo Programa de Pós-Graduação em Enfermagem da Universidade Federal do Rio Grande do Sul/UFRGS. Docente da Escola de Enfermagem da UFRGS. Membro do Grupo de Estudos do Cuidado à Saúde nas Etapas da Vida - CEVIDA. E-mail: hissi@hcpa.ufrgs.br

${ }_{* * * * *}$ Enfermeira. Docente da Escola de Enfermagem da Universidade Federal do Rio Grande do Sul/UFRGS. Membro do Grupo de Estudos do Cuidado à Saúde nas Etapas da Vida - CEVIDA. E-mail: nribeiro@hcpa.ufrgs.br

E****** Enfermeira. Docente do Curso de Graduação em Enfermagem e do Programa de Pós-Graduação em Enfermagem da Universidade Federal de Santa Maria/UFSM. Líder do Grupo de Pesquisa Cuidado à Saúde das Pessoas, Família e Sociedade -PEFAS. E-mail: stelamaris_padoin@hotmail.com
} 
com nova configuração de família para proporcionar conforto e proteção à criança ou ao adolescente que vive com HIV/AIDS.

Palavras chave: Saúde do adolescente, saúde da criança, HIV, adesão à medicação, família, enfermagem pediátrica.

\begin{abstract}
Objective: This study seeked to unveil the caregiver family member's perception regarding the daily medication in the perspective of the child and adolescent with HIV/AIDS. Method: This qualitative research was conducted using the creative and sensitive method and was developed in the municipalities of Porto Alegre and Santa Maria, RS, with the participation of 12 caregiver family members between 2006 and 2010 and approved by the Research Ethics Committee of the involved institutions. Results: From the thematic analysis, the following categories emerged: implications of the day-to-day medication for the families and family care while living with the disease. Upon the daily life of the child or adolescent with HIV/AIDS, the family perceives the difficulties of the antiretroviral treatment, the transition from childhood into adolescence, the multiple faces of living with HIV/AIDS. Conclusion: The family care occurs within a new family configuration to provide comfort and protection to the child or adolescent with HIV/AIDS.
\end{abstract}

Key words: Adolescent health, child health, HIV, medication adherence, family, pediatric nursing.

\title{
RESUMEN
}

Objetivo: Este estudio buscó develar la percepción del cuidador familiar en relación al cotidiano medicamentoso desde la perspectiva del niño y del adolescente que viven con VIH/SIDA. Material y método: Se realizó esta pesquisa cualitativa, con la utilización del método creativo y sensible, en las municipalidades de Porto Alegre y Santa María, RS, con la participación de 12 cuidadores familiares, desde 2006 hasta 2010, con aprobación del Comité de Ética en Investigación de las instituciones involucradas. Resultados: Del análisis temático emergieron las categorías: implicaciones del cotidiano medicamentoso para las familias y el cuidado familiar en la convivencia con la enfermedad. En el cotidiano del niño o del adolescente con VIH/SIDA, la familia percibe las dificultades del uso de antirretrovirales, la transición de la niñez hacia la adolescencia, las múltiples caras de vivir con VIH/SIDA. Conclusión: El cuidado familiar ocurre con nueva configuración de familia para proporcionar confort y protección al niño o al adolescente con VIH/SIDA.

Palabras clave: Salud del adolescente, salud del niño, VIH, adhesión a la medicación, familia, enfermería pediátrica.

Fecha recepción: 17/09/13. Fecha aceptación: 28/10/14.

\section{INTRODUÇÃO}

A epidemia da AIDS, complexa e dinâmica, exige a flexibilidade de novos desafios e tendências, pois a doença tem-se mostrado com múltiplas facetas desde o seu surgimen- to, com definições que evoluíram de grupo de risco, comportamento de risco até o conceito de vulnerabilidade, sendo uma resposta à epidemia. $\mathrm{O}$ Brasil apresentou avanços nas últimas décadas, entre os quais o acesso gratuito e universal ao Tratamento Antirretroviral (TARV), havendo a repercussão da 
mudança do perfil da doença que, de aguda, passou a apresentar características de cronicidade (1).

Nesse contexto, estão as crianças e adolescentes que vivem com HIV/AIDS, as quais possuem um cotidiano clínico permanente, com cuidados que envolvem acompanhamento ambulatorial, controle periódico de exames laboratoriais e a implementação de um esquema medicamentoso complexo. O esquema medicamentoso está associado à apresentação dos medicamentos, à posologia, aos efeitos adversos, características que influenciam o tratamento (1). Nesse cotidiano medicamentoso da criança e do adolescente a família -pai, mãe, irmãos ou avó- está sempre apoiando, confirmando se o tratamento está sendo realizado de forma correta e lembrando-os diariamente (2).

O cuidado no cotidiano do sistema familiar realizado sob o impacto da AIDS, doença com características crônicas, permeia alterações que podem transformar-se em sentimentos de valorização da vida e mudanças no cotidiano, o que desencadeia esse cuidado familial, o qual se volta para as pessoas do núcleo familiar que necessitam de atenção e cuidados com a saúde (3). Nesse núcleo, no mundo de cuidados com a criança e adolescente, ocorrem as definições e papéis de cada membro, no qual há proteção e cuidado (4).

A família que experiência a doença é formada pela união de seus membros, e os princípios que norteiam essa relação são o afeto, a lealdade, a responsabilidade com o outro, que desencadeiam uma relação social dinâmica perpassada por crenças, valores, normas de seu contexto sociocultural e situação histórica (5).

A relevância deste estudo está na complexidade que envolve as vivências das crianças e dos adolescentes que convivem com HIV/ AIDS em relação ao tratamento antirretroviral (TARV) junto à família. Considera-se que a família está repleta de vivências e experiências, com possibilidades de construir ações de cuidado à saúde da criança e adolescente, pois vivencia junto a ele as múltiplas facetas da fase do crescimento e desenvolvimento e da doença.

Nesse contexto, a Enfermagem que tem como essência o cuidado de pessoas, possui o compromisso de estar junto à criança, adolescente e família, construindo um cuidado que perpasse todas as dimensões humanas de maneira singular, conforme contextos e histórias de vidas.

O estudo foi desenvolvido nos municípios de Porto Alegre e Santa Maria, estado do Rio Grande do Sul (6). Optou-se por esses dois municípios considerando-se a alta taxa de detecção da doença e por se caracterizarem como centro de referência para o atendimento das Doenças Sexualmente Transmissíveis (DST) e HIV/AIDS das proximidades regionais. A pesquisa envolveu o método qualitativo e quantitativo, porém, para este artigo utiliza-se a fase qualitativa.

Aborda-se, portanto, a temática da adesão ao tratamento antirretroviral da criança e do adolescente na perspectiva da família, da criança e do adolescente, tendo como objetivo desvelar a percepção do familiar/cuidador em relação ao cotidiano medicamentoso na perspectiva da criança e do adolescente que vive com HIV/AIDS.

\section{MATERIAL E MÉTODO}

$\mathrm{Na}$ pesquisa, em sua fase qualitativa, utiliza-se o Método Criativo Sensível (MCS) como estratégia de coleta de informações. A coleta ocorreu a partir do desenvolvimento de dinâmicas de criatividade e sensibilidade (DCS) propostas pelo Método Criativo Sensível, o qual valoriza as singularidades de cada participante do grupo e a coletivização das experiências (7).

As etapas de campo da pesquisa foram desenvolvidas em serviços especializados em DST/AIDS no município de Porto Alegre, englobando: Serviço de Assistência Es- 
pecializada em DSTs e AIDS (SAE), Serviço de Atenção Terapêutica (SAT) do Hospital Sanatório Partenon, e Grupo de Atenção a AIDS Pediátrica do Ambulatório de Pediatria Hospital da Criança Conceição (GAAP). No município de Santa Maria foi o Serviço de Doenças Infecciosas Pediátricas do Hospital Universitário de Santa Maria (HUSM/ SM), no período de 2006 a 2010.

Os critérios de inclusão foram familiares/ cuidadores de crianças de zero a 12 anos ou adolescentes de 13 a 19 anos de idade, segundo critérios do Departamento DST/AIDS e Hepatites Virais do Ministério da Saúde, com diagnóstico de AIDS e em tratamento com antirretroviral por, pelo menos, três meses. Os participantes foram selecionados a partir da primeira etapa da pesquisa da fase quantitativa.

Os participantes do estudo foram 12 familiares/cuidadores, sendo um do sexo masculino e 11 do sexo feminino, com idades que variaram entre 16 e 80 anos. Em relação ao parentesco, foram identificados: bisavô, mães biológicas, mães adotivas, irmã e avó materna.

A coleta das informações ocorreu a partir da DCS que ocorreram em cinco momentos: no primeiro momento ocorreu a apresentação de cada membro do grupo, possibilitando a interação entre os participantes, pesquisadora e auxiliares de pesquisa, com a explanação das atividades a serem desenvolvidas. No segundo momento, a disponibilização dos materiais para realizar a dinâmica: papel pardo, lápis de cor, revistas para recorte de figuras. No terceiro momento, os participantes apresentaram suas produções artísticas individuais ou coletivas, socializando-as. Os temas sinalizados pelos participantes foram discutidos com os participantes que, no quarto momento, os decodificaram em subtemas durante a análise coletiva e a discussão grupal. Por fim, no quinto momento realizou-se a síntese temática dos temas e subtemas e a validação dos dados (7).

Foram realizadas três dinâmicas com du- ração aproximada de cinquenta minutos a uma hora e trinta minutos. As DCS foram coordenadas por um dos pesquisadores responsáveis pelo projeto e contaram com alunos da graduação e pós-graduação na função de auxiliares de pesquisa.

As dinâmicas desenvolvidas foram: Mapa Falante que consiste na produção de um mapa desenhado pelos participantes visando demonstrar suas redes de relações com a comunidade. Essa dinâmica teve como questão geradora de debate: Qual é o lugar do tratamento medicamentoso da criança no percurso do adoecimento? De que forma esse(s) lugar(es) são percebidos e vivenciados em sua história de familiares? E, a dinâmica Livre para Criar que consiste na criação artística livre, a partir de materiais lúdicos, a fim de responder as questões geradoras do debate, como: Quais as facilidades e dificuldades na administração do remédio da criança/adolescente?

Em relação à logística da pesquisa, os encontros foram previamente planejados, considerando-se a escolha do local apropriado e a previsão dos materiais a serem disponibilizados aos participantes.

O projeto de pesquisa foi aprovado pela Comissão Nacional de Ética em Pesquisa (CONEP) e Comitês de Ética em Pesquisa (CEP) das instituições envolvidas: CEP/ UFRGS, sob número 2005446; CEP/UFSM, sob número 23081.017341/2006-61; CEP/ SMS/POA, sob número 001014268.07.8; $\mathrm{CEP} / \mathrm{GHC}$, sob número 113/08. O estudo cumpriu com a proteção dos participantes quanto aos princípios da Resolução 196/96, e foi formalizado mediante o Termo de Consentimento Livre e Esclarecido (TCLE), assinado pelo responsável legal da criança ou adolescente que assegura a liberdade de participação espontânea e o direito de desistência em qualquer momento da pesquisa (8).

A análise Temática foi utilizada como estratégia de interpretação das informações, a qual incluiu três fases: a pré-análise, a exploração do material e o tratamento dos re- 
sultados obtidos e a interpretação (9). Os resultados apontaram as seguintes categorias: implicações do cotidiano medicamentoso para as famílias e o cuidado familial na convivência com a doença, sendo assegurado a credibilidade e consistência das informações.

\section{RESULTADOS}

\section{Implicações do cotidiano medicamentoso para as famílias}

No cotidiano medicamentoso, as medicações ARV fazem parte do cotidiano das famílias cujas crianças e adolescentes têm o HIV/ AIDS. Esse cotidiano perpassa as dificuldades de cumprir com o horário, fazer a criança tomar o remédio, e, quando necessário, as famílias utilizam estratégias para cumprir com a rotina medicamentosa.

[...] ele (refere-se a criança) tem que cumprir o horário [...] a gente tem horário pra tudo, como é que não vai ter horário pro medicamento? (C1).

Ele toma às sete da manhã e às sete da noite [...] sem problemas acordo ele e já dou junto com o copo de Nescau dele (C3).

[...] ela toma os remédio direitinho não precisa de nada porque se eu vou na casa da mãe, nós levamos o remédio e se tem que leva dois [...] eu levo dois [...] (C4).

Ainda nesse cotidiano medicamentoso, os familiares referem-se a dificuldades como: gosto da medicação, tamanho do comprimido e os efeitos colaterais. Salienta-se o uso do leite como necessário para a ingestão da medicação, o que nem sempre é disponibilizado para a criança por motivos econômicos.

Ela diz (refere-se à criança): 'fica um gosto ruim na boca' [...] ela disse que dá dor no estômago dela, mas ela toma igual [...] 'mãe esse óleo dá dor de barriga mãe!' (C4).
A dificuldade da minha filha, um medicamento só o Kaletra acho que vocês que tão aqui conhecem porque ele é um remédio grande [...] só com leite [...] ás vezes eu não tenho como dá pra ela [...] se ela tomar com água ou com suco ela vomita tudo entendeu? Até eu vou ter que pedir pro doutor trocar porque ta sendo muito difícil (C6).

A maioria dos familiares relata que as crianças e adolescentes tomam as medicações, e narram as estratégias utilizadas para que não haja falhas no tratamento, entre as quais: a contagem dos comprimidos, a dosagem da medicação e a colocação do despertador para lembrar o horário da medicação. $\mathrm{O}$ familiar cuidador relata a estratégia de ficar junto com o filho/filha até a ingestão total da dose. E utiliza sua vivência para negociar com o filho.

De manhã e antes de ele sair ele toma quando eu vou contar a medicação e sobra [...] ele diz 'não, mas eu tomei' [...] foi onde ele começou a vê que eu tava realmente contando [...] eu comecei a cortar as coisas que ele gostava como futebol [...] não tem responsabilidade com o horário que é só de manhã [...] consegui que a coisa voltasse ao normal (C1).

É uma benção ele tomar o medicamento, eu que dou pra ele [...] se eu tenho que sair ele bota o celular a despertar (C3).

Ela me enganou né? Eu disse pra ela tomar, eu virei as costas, ela pegou e botou fora o remédio [...] daí eu tive que ficar na frente dela pra ela tomar (C6).

'tem que tomar' [...] Eu não gosto muito de tomar remédio, mas vo lá pego, tomo e deu [...] (C11).

Nessa perspectiva, alguns cuidadores relataram que reconhecem os resultados positivos do tratamento. Esperam, que com a adesão, a criança ou o adolescente possa ter qualidade de vida à semelhança daquelas que não têm o vírus, além de manter a carga viral baixa e o CD4 alto. 
Ele joga bola, ele anda de bicicleta (C3).

Tá dando indetectável os exame dela (C4)

Descobriram (o tratamento) pra controlar (a doença) e só não têm pra...(curar) [...] tava bem alto esse vírus nela, 2000 e pouco, isso ai faz algum tempo, ai quando eu passei a cuidar dela baixou bastante [...] Sem o remédio ela não pode ficar (C10).

É provável que para o familiar a prática de atividades recreativas -jogar bola e andar de bicicleta- seja um indicativo de que a criança está bem, e, de maneira semelhante, quando o resultado do exame demonstra uma carga viral indetectável.

\section{Cuidado familial na convivência com a do- ença}

O cuidado familial foi percebido como um processo de retomada e reorganização da unidade de cuidado que representa a família. Os familiares/cuidadores frequentemente inserem a religiosidade em sua vida, atribuem ao divino o poder da cura ou a intermediação com a equipe de saúde. A fé, a espiritualidade e a esperança de cura apresentam-se como elementos facilitadores para a construção de processos de enfrentamento.

Eu acredito que antes de mim tem um Deus um ser iluminado que colocou médicos aqui, enfermeiras que iam conseguir me ajudar (C1).

Se continua creio que Deus vai abençoar ele (C3).

Disse que quer que Jesus salve ela [...] A gente vai todas as semanas (igreja) [...] Ela vai junto nos domingos comigo de manhã... Está sendo uma benção (C4).

A facilidade [...] a gente tem bastante fé em Deus e esperamos que venha junto com a nossa força de vontade a cura. Que venha logo pra todos nós portadores [...] Diz que tava pra vir a cura? (C6).

Entre os enfrentamentos do familiar/cui- dador da condição sorológica, tem-se, ainda, o período de transição da infância para a adolescência que geralmente traz consigo a necessidade de adequação familiar a partir do diálogo, pois, ora o filho tem comportamento infantil ora comportamento semelhante ao adulto.

Só que eu acho que a responsabilidade de fazer ele entender as coisas não é dele. Ele não tem essa noção. Então, eu tenho que fazer tudo isso e eu faço tudo isso com amor [...] Hoje ele já tem essa noção, tanto que eu já estou preparando ele (C1).

A (refere-se a criança) ela toma sozinha o remédio, ela sabe que é dois copinho cor-de-rosa de noite, dois copinho de manhã e três cápsula. Ela sabe tudinho. Ela sabe que é duas de manhã e três de noite (as cápsulas) e o óleo (C4).

A mãe querendo que o filho tome o remédio $e$ o filho não quer tomar [...] eu ia dize o que pra ele? toma que é o mesmo gostinho que suco, não né, então toma por causa do famoso bichinho sobe e desce (C5).

No diálogo acerca do uso de medicações, os familiares também demonstram a necessidade de falar acerca do uso de preservativos. A informação precoce visando à preservação da qualidade de vida e à incorporação de hábitos saudáveis preocupa os familiares.

Eu já to agora entrando num outro caminho que é o uso da camisinha tem que preservar a outra pessoa, eu acho que tudo isso né? Então ta indo, ta indo (C1).

Aquela questão sobre preservativo, tudo ele (refere-se à criança) já na escola mesmo ele já fez trabalho se eu não tivesse contado até para ele ia se um baque na escola, ele já fez trabalho sobre (C3).

Ainda como recursos facilitadores, a família explicita poder contar com atendimento de saúde, equipe preparada para acolher suas necessidades e prontidão na obtenção da me- 
dicação para uso da criança ou adolescente.

Facilidade pra mim ficou [...] médico, postinho médico (C1).

Todo o pessoal que me atende aqui, que sou bem recebido, e nunca me faltou remédio pra minha filha! (C12).

Quando ela ta tomando o remédio que ta na metade, eu já to aqui (serviço de saúde) pra pegar o remédio, já peguei já, já tem pra dois mês ou mais, não espera termina o remédio (C10).

Entre as implicações do surgimento da doença na vida da família destaca-se a reorganização da estrutura sociofamiliar, que inclui a dedicação quase que exclusiva aos cuidados da criança e ao adolescente.

Aí eu abri mão do emprego também né? [...] eu preciso chegar mais tarde porque meu filho tem médico [...] Nada é mais importante do que a vida e a saúde do meu filho. Emprego eu consigo outro, e filho eu só tenho um (C1).

Não trabalho porque eu não tenho condições, meu filho toma medicamento às cinco da manhã, nove da manhã, uma da tarde, nove da noite (C2).

Salienta-se que a família tem papel fundamental no tratamento, associado ao amor e ao apoio que oferecem à criança ou adolescente, sendo vital na busca do bem-estar.

Eu coloquei amor dentro de um coração. Eu acho até que ele tem amor demais [...] Ele é meu tudo [...] Eu acho que a responsabilidade de educar e de fazer ele entender as coisas é minha [...] Eu acho que onde existe amor, uma base, um equilíbrio [...] (C1).

A margarida representa a flor que ela é pra mim [...] Desenhei a minha querida neta, com uma margarida ela adora ta no meio das flor [...] A gente faz isso com amor né? [...] (C10).

Que a gente cuida bem [...] gostamos muito dela, é sofrido né essa doença? (C9).

\section{DISCUSSÃO E CONCLUSÃO}

Frente aos resultados apresentados na categoria Implicações do cotidiano medicamentoso para as famílias, percebe-se que a manutenção do tratamento antirretroviral é peculiar a cada família, pois algumas crianças aceitam passivamente o tratamento, não apresentam resistência para tomar as medicações, mesmo que devam tomá-las fora de casa.

As pessoas que fazem uso de ARV, que possuem os horários diários programados, muitas vezes têm mais facilidade de aderirem (10). A estratégia comum usada para a rotina diária das medicações é associar o horário da medicação à sua rotina: ao levantar de manhã, ao tomar o café, ao jantar, ou ao alimentar seu animal de estimação. É importante criar caminhos para o uso do medicamento associados aos horários diários de sua rotina. Em contraponto, para pessoas com horários desorganizados torna-se mais difícil essa estratégia, e a complexidade do regime terapêutico pode interferir nas atividades cotidianas dos pacientes (11).

Quanto às dificuldades relatadas no cotidiano medicamentoso para a sua ingestão, um estudo realizado com familiares e pessoas com HIV revela que, às vezes, algum tipo de alimento após a ingestão do medicamento pode facilitar a adesão ao ARV (3). Nesse sentido, destaca-se a necessidade de estratégias para a ingestão de alimentos com o uso dos medicamentos (12).

A complexidade dos regimes terapêuticos pode resultar em dificuldades em desenvolvê-los, o que repercute na adesão, e isso ocorre tanto em função da adaptação aos horários quanto às restrições alimentares. Tomar o medicamento no trabalho ou na escola e as características da formulação são considerados impedimentos para a criança ou o adolescente (13), e, do mesmo modo, a dificuldade em dissolvê-lo ou em engoli-lo, além 
da intolerância ao cheiro e ao gosto $(14,15)$.

Nessa direção, a falha na aderência ao tratamento com ARV pode ser resultado de falta de motivação e intolerância aos efeitos colaterais (11). Os efeitos colaterais -náuseas, vômitos, dores de cabeça e diarreia- são dificuldades diretamente relacionadas à baixa adesão (14).

O familiar/cuidador manifesta o cuidado com o uso correto dos antirretrovirais, com a continuidade efetiva do tratamento. Em alguns momentos, o familiar/cuidador também tem o vírus, e necessita realizar o próprio tratamento, referindo-se a ele também de maneira negativa em sua vida. No entanto, o uso dos antirretrovirais pode repercutir na vida de algumas pessoas de modo menos traumático e possuir um caráter positivo e tranquilo, o que dependerá do significado atribuído a essa condição. Estudo realizado com familiares cuidadores de criança com o vírus apontou que eles buscam desenvolver uma rotina em que os medicamentos possuam características naturalizadas, subsidiadas pelo desenvolvimento do imaginário da criança (16).

O reconhecimento dos resultados positivos do cotidiano medicamentoso repercute na qualidade de vida da população. Nesse contexto, vale lembrar que o cuidado com a saúde, ou seja, a condição clínica da criança esteja ancorada no uso dos medicamentos de maneira adequada, o que reflete em um cuidado que o familiar/cuidador realiza junto à criança e ao adolescente, concretizado nos resultados de exames laboratoriais e no crescimento e desenvolvimento saudável desses. $O$ produto do tratamento está nas manifestações de ser criança e adolescente: viver como as outras crianças e adolescentes, brincando, estudando, chorando, sonhando e relacionando-se (17), manifestações de ser e estar no mundo consigo e com os outros.

$\mathrm{Na}$ categoria Cuidado familial na convivência com a doença, para não esmorecer diante das dificuldades que surgem quando a criança/adolescente adoece, as famílias bus- cam formas de enfrentamento, com elementos facilitadores (18). Percebe-se a inserção da religiosidade na vida dessas famílias. A religião, muitas vezes, é um recurso facilitador para a adesão (19). A procura da espiritualidade é utilizada como forma de apoio para que as pessoas sigam a sua trajetória ou a modifiquem para enfrentar a nova situação frente à doença. Na maioria das vezes, as pessoas que vivem com AIDS utilizam a espiritualidade como apoio para enfrentar os sofrimentos após o diagnóstico, e encontram na religião o conforto, a ajuda e a esperança para viverem (18).

Quanto aos enfrentamentos frente à condição sorológica, destaca-se que a família deve estar preparada para as características do desenvolvimento dos filhos, principalmente na transição da infância para a adolescência, quando podem surgir as dúvidas e o interesse pelas questões sexuais. Estudo com adolescentes que têm AIDS, mostrou que, no estar adolescendo e ter AIDS, há implicações no vivenciar da sexualidade, que repercuti no silêncio do seu diagnóstico, em vista de perspectivas futuras (20). O silêncio faz-se presente no mundo da família e do adolescente, no sentido de gerenciar o estigma, pois o silêncio pode minimizar ou fortalecer tais situações de discriminação e preconceito (21).

Nesse sentido os familiares/cuidadores devem estar atentos e se anteciparem às necessidades concretas dos adolescentes para que estejam orientados e preparados quando iniciarem a atividade sexual. Com isso, os processos com enfoque educacional poderão apoiar o paciente no processo terapêutico e fortalecer sua autonomia (22).

Acredita-se que para o sucesso da adesão será necessário o comprometimento dos serviços de saúde, em especial quanto ao vínculo e ao acolhimento eficiente, eficaz e resolutivo. Considera-se que para a manutenção de altas taxas de adesão são fundamentais intervenções personalizadas a partir de práticas comportamentais e cognitivas (23). Sendo fundamental identificar necessidades 
de adaptações na rotina medicamentosa do adolescente para a qualidade e adesão ao tratamento (24).

Assim, a qualidade da assistência requer o empenho de ouvir, interagir, conscientizar e adequar a linguagem (22). Outro fator importante para a aderência medicamentosa é o relacionamento entre o paciente e o provedor principal de seu cuidado. A adesão, geralmente, é menor se a comunicação e a interação entre o paciente e o profissional de saúde forem deficientes (25).

Frente às implicações do surgimento da doença como a reorganização da estrutura sociofamiliar para o cuidado à criança e/ou adolescente, percebe-se que muitas vezes, os familiares/cuidadores abrem mão do trabalho para assumir integralmente os cuidados cotidianos com seus filhos, imbuídos de genuíno afeto como mecanismo propulsor dessas condutas. Normalmente, a dedicação exclusiva ao cuidado de crianças clinicamente frágeis pelos familiares cuidadores é essencialmente desenvolvida por mulheres, partindo da determinação sociocultural em que elas são responsabilizadas e/ou culpabilizadas pelo estado de saúde da criança (26).

O papel fundamental no cotidiano medicamentoso repercute na família, visto que esta reorganiza-se e reforça sua função de proteção com a criança e o adolescente no mundo, ratifica-se como fonte de afeto, segurança e apoio, visualizando a esperança como auxílio terapêutico (25). A família, no contexto do HIV/AIDS, desenvolve o cuidado familial, o qual norteia as ações de cuidado voltadas para o bem-estar da criança e do adolescente. $\mathrm{O}$ cuidado possibilita às famílias se descobrirem e serem no mundo, a partir de suas experiências e vivências de vida associadas às demandas da doença de seus membros. Com isso, as famílias cuidadoras apresentam uma nova configuração, sendo fundamental a consideração de valorização das potencialidades das crianças ou adolescentes para a promoção de um cuidado pleno (27, 28).
Em relação à percepção do familiar/cuidador em relação ao cotidiano medicamentoso na perspectiva da criança e do adolescente que vive com HIV/AIDS, aponta-se algumas dificuldades em relação ao tratamento antirretroviral que podem resultar em não adesão. Entre as dificuldades manifestadas pela família estão: cumprir o horário, aceitação pela criança e pelo adolescente em tomar o remédio, o gosto da medicação e o tamanho dos comprimidos, além dos efeitos colaterais. Outra dificuldade associada às demais está relacionada ao baixo poder aquisitivo que, muitas vezes, não permite a compra do leite e/ou outros alimentos que podem auxiliar a ingestão da medicação.

As estratégias adotadas pelas famílias para diminuir estas dificuldades são peculiares a cada uma delas, e incluem: compartilhar a responsabilidade do tratamento com a própria criança/adolescente, controle do número de comprimidos restantes e a sobra do volume no frasco, o uso do despertador para lembrar o horário da medicação até a vigilância direta da ingestão total da dose. Em algumas situações há a necessidade de atitude mais incisiva, como a retirada de privilégios caso a criança/adolescente não tenha uma adesão adequada. Quanto aos efeitos colaterais das medicações, os familiares manifestam preocupação constante e a intenção de solicitar substituição das medicações que desencadeiam efeitos colaterais.

No que se refere ao cuidado familial na vivência com o HIV/AIDS, o discurso das famílias/cuidadores aborda os recursos facilitadores da construção do processo de enfrentamento: a fé, a espiritualidade e a esperança de cura. No entanto, o cuidado relacionado às necessidades da fase infantil e da adolescência não é negligenciado, pois, a preocupação com o momento existencial vivido por eles, individualmente, o preparo para o cuidado de si e a busca da qualidade de vida visa o futuro dos filhos.

Para que o cuidador/familiar se fortaleça nessa caminhada junto à criança e ao adoles- 
cente que vive com o HIV/AIDS é necessário reorganizar-se e, com frequência, abrir mão do trabalho para assumir integralmente seus cuidados. Essas famílias devem contar com profissionais enfermeiros comprometidos e implicados com um cuidado sensível e autêntico, com espaços dialógicos centrados no vínculo e no acolhimento, a fim de acolher e valorizar suas necessidades em suas múltiplas dimensões sociais, econômicas e existenciais.

\section{REFERENCIAS}

1. Ribeiro AC, Paula CC, Neves ET, Padoin SM. Perfil clínico de adolescentes que têm AIDS. Cogitare Enferm. 2010; 15(2): 25662.

2. Botene DZ, Pedro EN. Implicações do uso da terapia antirretroviral no modo de viver de crianças com Aids. Rev Esc Enferm USP. 2011; 45(1): 108-15.

3. Silva AL, Waidman MA, Marcon SS. Adesão e não-adesão à terapia anti-retroviral: as duas faces de uma mesma vivência. Rev Bras Enferm. 2009; 62(2): 213-220.

4. Schaurich D, Freitas HM. O referencial de vulnerabilidade ao HIV/AIDS aplicado às famílias: um exercício reflexivo. Rev Esc Enferm USP. 2011; 45(4): 989-995.

5. Schaurich D, Coelho DF, Motta MG. A cronicidade no processo saúde-doença: repensando a epidemia da AIDS após os anti-retrovirais. Rev. enferm. UERJ. 2006; 14(3): 455-462.

6. Motta MGC, Pedro ENR, Padoin SMM, Ribeiro NRR, Issi HB, Paula CC, et al. Impacto de Adesão ao tratamento antirretroviral em crianças e adolescentes na perspectiva família da criança e adolescente. (Projeto de Pesquisa) Projeto Financiado pelo Programa Nacional de HIV/AIDS/DST do Ministério e Organização das Nações Unidas para a Educação, Ciência e a Cultura. Universidade Federal do Rio Grande do Sul. Porto Alegre:
UFRGS 2009; 199 p.

7. Cabral IEO. Método criativo e sensível: alternativa de pesquisa na enfermagem. In: Gauthier JHM, Cabral IE, Santos I, Tavares CMM. Pesquisa em Enfermagem: novas metodologias aplicadas. Rio de Janeiro: Guanabara Koogan; 1998. p. 177-208.

8. Ministério da Saúde (BR). Conselho Nacional de Saúde. Diretrizes e normas regulamentadoras de pesquisa envolvendo seres humanos. Resolução no 196 de 10 de outubro de 1996. Brasília (DF): Ministério da Saúde; 1996.

9. Minayo MC. O desafio do conhecimento: pesquisa qualitativa em saúde. São Paulo: Hucitec; 2010. 407 p.

10. Santos WJ, Freitas E; Da Silva A, Marinho C, De Fátima M. Barreiras e aspectos facilitadores da adesão à terapia antirretroviral em Belo Horizonte-MG. Rev Bras Enferm. 2011; 64(6): 1028-1037.

11. Almeida EL, Araújo GB, Santos VA, Bustorff LA, Pereira AV, Dias MD.Adesão dos portadores do HIV/AIDS ao tratamento: fatores intervenientes. Rev. Min. Enferm. 2011; 15(2): 208-216.

12. Gomes AM, Cabral IE. Ocultamento e silenciamento familiares no cuidado à criança em terapia antirretroviral. Rev Bras Enferm. 2010; 63(5): 719-26.

13. Kourrouski MF, Lima RA. Adesão ao tratamento: vivências de adolescentes com HIV/AIDS. Rev Lat Am Enfermagem. 2009; 17(6): 947-952.

14. Melchior R, Nemes MI, Alencar TM, Buchalla CM. Desafios da adesão ao tratamento de pessoas vivendo com HIV/ AIDS no Brasil. Rev Saude Publica. 2007; 41(2): 87-93.

15. Martins SS, Martins TS. Adesão ao tratamento antirretroviral: vivências de escolares. Texto contexto-enferm. 2011; 20(1): 111-118.

16. Gomes AM, Cabral IE. O cuidado medicamentoso à criança com HIV: desafios e dilemas de familiares cuidadores. Rev 
Bras Enferm. 2009; 62(2): 252-7.

17. Paula CC, Crossetti, MG. Existencialidade da criança com AIDS: perspectivas para o cuidado de Enfermagem. Esc. Anna Nery. 2008; 12(1): 30-8.

18. Machiesqui SR, Padoin SM, Paula CC, Ribeiro AC, Langendorf TF. Pessoas acima de 50 anos com aids: implicações para o dia-a-dia. Esc. Anna Nery. 2010; 14(4): 726-731.

19. Teixeira MG, Silva GA. A representação do portador do vírus da imunodeficiência humana sobre o tratamento com os anti-retrovirais. Rev Esc Enferm USP. 2008; 42(4):729-736.

20. Paula CC, Cabral IE, Souza IE. O cotidiano do ser-adolescendo com aids: movimento ou momento existencial? Esc. Anna Nery. 2009; 13(3): 632-9.

21. Fielden SJ, Chapman GE, Cadell SD. Managing stigma in adolescent HIV: Silence, secrets and sanctioned spaces. Cult Health Sex. 2011; 13(3): 267-281.

22. Ceccato MG, Acurcio FA, César CC, Bonolo PF, Guimarães MD. Compreensão da terapia anti-retroviral: uma aplicação de modelo de traço latente. Cad Saude Publica. 2008; 24(7): 1689-1698.

23. Thurston IB, Bogart LM, Wachman M, Closson EF, Skeer MR, Mimiaga MJ.
Adaptation of an HIV Medication Adherence Intervention for Adolescents and Young Adults. Cogn Behav Pract. 2014; 21(2): 191-205.

24. Mesquita NF, Torres OM. A equipe de saúde na atenção integral ao adolescente vivendo com HIV/AIDS. Esc. Anna Nery. 2013; 17(4): 730-739.

25. Guaragna BF, Ludwig ML, Cruz AL, Graciotto A, Schatkoski AM. Implantação do programa de adesão ao tratamento de HIV/AIDS: Relato de experiência. Rev HCPA. 2007; 27(2): 35-8.

26. Neves ET, Cabral IE. Cuidar de crianças com necessidades especiais de saúde: desafios para as famílias e enfermagem pediátrica. Rev. Eletr. Enf. 2009; 11(3): 52738.

27. Motta MG, Issi HB, Ribeiro NR. Grupos como estratégia de ensino e cuidado de família, criança e adolescente com doença crônica. Cienc Cuid Saude. 2009; 8(Supl): 155-161.

28. Motta MGC, Issi HB, Milbrath VM, Ribeiro NRR, Resta DGR. Famílias de crianças e adolescentes no mundo do hospital: ações de cuidado. En: Elsen I, Souza AIJ, Marcon SS. Enfermagem à família: dimensões e perspectivas. 1ra edição. Maringá (PR): Eduem; 2011. p. 73-85. 